This material is posted here with permission of the IEEE. Such permission of the IEEE does not in any way imply IEEE endorsement of any of Helsinki University of Technology's products or services. Internal or personal use of this material is permitted. However, permission to reprint/republish this material for advertising or promotional purposes or for creating new collective works for resale or redistribution must be obtained from the IEEE by writing to pubs-permissions@ieee.org.

By choosing to view this document, you agree to all provisions of the copyright laws protecting it. 


\title{
Nucleation Kinetics and Solidification Temperatures of SnAgCu Interconnections during Reflow Process
}

\author{
H. Yu and J. K. Kivilahti, Fellow, IEEE \\ Laboratory of Electronics Production Technology \\ Helsinki University of Technology \\ PL 3000/P.O.Box 3000 \\ FIN- 02015 HUT, Finland
}

\begin{abstract}
The nucleation kinetics of $\beta$-Sn in liquid $\mathrm{SnAgCu}$ interconnections was simulated on the basis of nucleation theory. After evaluations of the compositions of liquid solder interconnections during reflow soldering, the free energy of nucleation can be calculated thermodynamically. Since homogeneous nucleation rate is very low, the mechanism that initiates solidification of interconnections is the heterogeneous nucleation at the $\mathrm{Liq} / \mathrm{Cu}_{6} \mathrm{Sn}_{5}$ interface and the corresponding nucleation rates in interconnections are therefore simulated. Additional simulation of the nucleation rate in a tin droplet was also done to determine a critical range of nucleation rate. The contact angle for the heterogeneous nucleation was evaluated with the help of recent DSC measurements. The simulations allow us to evaluate the actual solidification temperature of interconnections, which is a fundamental parameter in studying the formation of solidified microstructure in solder interconnections. The variation of the solidification temperature with cooling rate, interconnection size, and morphology of intermetallic compounds is also discussed. Even though the actual solidification temperatures of interconnections depend on Ag-content, the supercooling range is shown to be fairly constant $\left(18-20^{\circ} \mathrm{C}\right)$, which offers a possibility to predict the actual solidification temperature of interconnections via phase equilibria information.
\end{abstract}

\section{INTRODUCTION}

The importance of the reliability of soldered assemblies is increasing with the greater demands on functionality and performance of electronic equipment. Product reliability is especially important in portable electronics, because this more powerful and complex electronic equipment experiences, in addition to operational stresses, various kinds of mechanical, thermo-mechanical and chemical strains in the service environment. The reliability of soldered assemblies ultimately depends on the microstructures of the interconnections, the evolution of which is affected sensitively by temperature, stress and current density. Knowledge of the solidification structure formed in soldering operation is thus of primary importance in understanding how interconnection microstructures evolve with time. It is the as-solidified microstructure that determines the onset properties of solder interconnections. When the microstructure changes, the properties of the interconnections will change, both during reliability testing and product use ${ }^{[1]}$. There is good reason, therefore, to investigate the solidification of multicomponent solder interconnections by employing theoretical approaches involving concurrent use of thermal, thermodynamic and kinetic modelling tools and microstructural characterization techniques.

Solidification is the result of two successive steps: nucleation and growth of solid phase. In nucleation, the solder system has to overcome an energy barrier, and the liquid solder must supercool down to the so-called solidification temperature at which the solid phase first starts to form. The amount of supercooling, that is, the 
difference between the actual and equilibrium solidification temperatures, depends on the nucleation kinetics. High-level supercooling can be achieved in tiny droplets. For example, supercooling up to $105^{\circ} \mathrm{C}$ has been observed in pure tin droplets with diameters ranging from $1 \mu \mathrm{m}$ to $10 \mu \mathrm{m}^{[2]}$. Since interconnections are very much smaller than typical bulk castings, their supercooling during the reflow soldering cannot be neglected. This has been confirmed by recent DSC measurements ${ }^{[3]}$, which revealed that $\mathrm{SnAgCu}$ solder droplets in copper pans solidify at temperatures much lower than the liquidus temperature. It is important therefore to know the exact actual solidification temperatures of interconnections.

Although three phases form during the solidification of near-eutectic $\mathrm{SnAgCu}$ solders - $\beta$-Sn, $\mathrm{Cu}_{6} \mathrm{Sn}_{5}$ and $\mathrm{Ag}_{3} \mathrm{Sn}$ - the amounts of $\mathrm{Cu}_{6} \mathrm{Sn}_{5}$ and $\mathrm{Ag}_{3} \mathrm{Sn}$ are limited and more than 95 vol.\% of the solidified interconnections is $\beta$-Sn, including both primary and eutectic tin. From this it can be concluded that the level of supercooling of interconnections is controlled by the kinetics of $\beta$-Sn nucleation.

On the basis of classical nucleation theory ${ }^{[4,5]}$, we study the nucleation kinetics of $\beta$-Sn formation in $\mathrm{SnAgCu}$ interconnections and thus predict the actual solidification temperature of interconnections in this paper. This is necessary in studying the formation of cells, dendrites, and colonies as well as other microstructural units in as-solidified solder interconnections. Our aim is, by combining this analysis with those of the thermal and thermodynamic simulations that we presented earlier ${ }^{[6,7]}$, to be able to predict and control solidification structures and so, ultimately, the reliability of solder interconnections.

\section{LIQUID COMPOSITION OF INTERCONNECTIONS}

Before we can analyze the kinetics of $\beta$-Sn nucleation, we need to know the liquid composition of interconnections. When a solder interconnection is melted during reflow soldering, the liquid spreads over the soldering pads on both component and printed wiring board. Intermetallic layers, such as $\mathrm{Cu}_{6} \mathrm{Sn}_{5}$ and $\mathrm{Cu}_{3} \mathrm{Sn}$, form rapidly at the interface between bulk solders, component metallizations and boards/metal finishes. The thickness of $\mathrm{Cu}_{6} \mathrm{Sn}_{5}$ layer increases with time but is limited to several microns, so the major part of the interconnections remains liquid. Massive solidification occurs only when $\beta$-Sn starts to form.

The $\mathrm{Cu}_{6} \mathrm{Sn}_{5}$ layer grows gradually before the massive solidification occurs during reflow soldering. According to the concept of local equilibrium, the liquid composition at the $\mathrm{Liq} / \mathrm{Cu}_{6} \mathrm{Sn}_{5}$ interface should acquire such a value that the liquid is in local equilibrium with $\mathrm{Cu}_{6} \mathrm{Sn}_{5}$. This value is evidently not the original composition of solder interconnections.

During directional growth of a solid into a large amount of liquid, the composition in liquid varies continuously within the boundary layer at the front of the solid/liquid interface. The characteristic thickness of the boundary layer can be calculated as $2 D / v^{[8]}$, where $v$ is the velocity of the moving solid/liquid interface and $D$ is the diffusion coefficient of the solute atoms. For the growth of $\mathrm{Cu}_{6} \mathrm{Sn}_{5}$ occurring in reflow soldering, since the growth is parabolic ${ }^{[9]}$ and the final thickness of $\mathrm{Cu}_{6} \mathrm{Sn}_{5}$ is typically several microns, the velocity of the $\mathrm{Liq} / \mathrm{Cu}_{6} \mathrm{Sn}_{5}$ interface is less than $10^{-7}$ $\mathrm{m} / \mathrm{s}$. Further, since the diffusion coefficients of solute atoms in liquid are on the order of $10^{-9} \mathrm{~m}^{2} / \mathrm{s}$, the characteristic thickness of the boundary layer must be at least several centimeters, which significantly exceeds the sizes of both interconnections and DSC samples. Evidently, it means that solute atoms diffuse in interconnections rapidly enough to keep the liquid composition uniform. The compositions of the liquid 
interconnections is therefore determined by the equilibrium between liquid and $\mathrm{Cu}_{6} \mathrm{Sn}_{5}$.

It follows that liquid compositions of interconnections vary with the temperature during reflow soldering. Fig. 1 plots the isothermal sections of the SnAgCu phase diagram calculated by using a thermodynamic databank system. ${ }^{[10]}$ In order to evaluate the composition of the liquid before $\mathrm{Sn}$ nucleation, $\beta$-Sn has been suspended in the case of the metastable liquid being supercooled. The composition of the liquid being equilibrium with $\mathrm{Cu}_{6} \mathrm{Sn}_{5}$ lies on the boundary between the $\mathrm{L}$ and $\mathrm{L}+\mathrm{Cu}_{6} \mathrm{Sn}_{5}$ regions in the diagram. Because the amount of intermetallic layers is limited compared with the interconnections, Ag content of the liquid can be assumed to be constant. Therefore, for an interconnection with the original composition at $a$, the liquid composition after the formation of $\mathrm{Cu}_{6} \mathrm{Sn}_{5}$ is shifted to $b$ at $230^{\circ} \mathrm{C}$ and varies along $b$ - $b$ ' with temperature. Fig. 2 shows the calculated $x_{C u}$ as functions of temperature for interconnections with different silver contents $x_{A g}=0.0065,0.01$, and 0.02 .

In the above, it is assumed that $\mathrm{Ag}_{3} \mathrm{Sn}$ cannot form before the nucleation of $\beta$ Sn, which is true for interconnections with low silver content. Fig.3 shows the temperature at which the driving force for independent $\beta$-Sn or $\mathrm{Ag}_{3} \mathrm{Sn}$ nucleation appears. The temperature for $\beta-\mathrm{Sn}$ is between 210 and $230^{\circ} \mathrm{C}$, whereas the temperature for $\mathrm{Ag}_{3} \mathrm{Sn}$ remains lower than $170^{\circ} \mathrm{C}$ until $\mathrm{Ag}$ content exceeds 0.02 .

In interconnections with high Ag content, in contrast, $\beta$-Sn nucleation may occur either before or after $\mathrm{Ag}_{3} \mathrm{Sn}$ formation. Owing to insufficient data for $\mathrm{Ag}_{3} \mathrm{Sn}$ formation, the competition between $\beta$-Sn and $\mathrm{Ag}_{3} \mathrm{Sn}$ nucleation cannot be simulated. The problem can be circumvented, however, by investigating the $\beta$-Sn nucleation under two different conditions: 1) $\mathrm{Ag}_{3} \mathrm{Sn}$ does not nucleate before $\beta$-Sn and the liquid composition varies in the same manner as interconnections with low Ag content; 2) $\mathrm{Ag}_{3} \mathrm{Sn}$ forms as long as there is driving force for its nucleation, and the liquid composition vary along $c-c^{\prime}$ rather than $b-b$ ' in Fig. 1 because there is a three-phases (liquid, $\mathrm{Ag}_{3} \mathrm{Sn}, \mathrm{Cu}_{6} \mathrm{Sn}_{5}$ ) equilibrium. The temperature range for the initiation of solidification can be then determined by combining these two simulated results. Fig. 4 shows the calculated liquid composition under the two conditions when $x_{A g}=0.035$.

\section{FREE ENERGY OF NUCLEATION}

In nucleation, the solder system has to overcome a certain energy barrier, known as the free energy of nucleation. In classical nucleation theory ${ }^{[4,5]}$, the free energy of nucleation is

$$
\Delta G=\frac{16}{3} \frac{\pi \sigma^{3}}{\Delta g^{2}}
$$

where $\sigma$ is the interfacial energy of the solid/liquid interface, $\Delta g$ is the Gibbs free energy difference between liquid and solid per unit volume. Accordingly, only those nuclei having sizes larger than a critical value can grow successfully and become effective nuclei, which initiate solidification. The critical size of nucleus, $r^{*}$, is

$$
r^{*}=-\frac{2 \sigma}{\Delta g}
$$

Since $\sigma$ and $\Delta g$ determine the free energy of nucleation, their values for liquid solders are discussed in this section.

1) Gibbs Free Energy Difference $\Delta g$ 
The free energy change occurring during solidification is the sum of the chemical potential differences between solid and liquid for all the components. For pure metal, it equals the change in chemical potential per mole $\Delta \mu$ divided by the molar volume $V_{m}$ of solid

$$
\Delta g=\Delta \mu / V_{m}
$$

For a multi-component alloy, average values can be used for the quantities involved. For a near-eutectic SnAgCu solder system,

$$
\Delta g=\left(x_{S n}^{S} \Delta \mu_{S n}+x_{A g}^{S} \Delta \mu_{A g}+x_{C u}^{S} \Delta \mu_{C u}\right) / \overline{V_{m}}
$$

Here $\Delta \mu_{i}$ is the change in chemical potential for a component $i$, and $x_{i}^{S}$ is the mole fraction of the component $i$ in $\beta$-Sn. Since the solubility of $\mathrm{Ag}$ and $\mathrm{Cu}$ in $\beta$-Sn is negligible, Equation (4) is simplified to

$$
\Delta g \approx \Delta \mu_{S n} / V_{m}=\left(\mu_{S n}^{S}-\mu_{S n}^{L}\right) / V_{m}
$$

with $\mu_{S n}^{S}$ and $\mu_{S n}^{L}$ denoting the chemical potential of $\mathrm{Sn}$ in solid and liquid, respectively. It is to be noticed that the chemical potential $\mu_{S n}^{L}$ depends on the composition of liquid phase as shown above, while the chemical potential $\mu_{S n}^{S}$ can be regarded as constant at a certain temperature because of low silver and copper contents in $\beta$-Sn. Fig. 5 shows the calculated $\Delta \mathrm{g}$ values with different Ag contents by using the thermodynamic databank system ${ }^{[10]}$.

2) Interfacial Energy $\sigma$

In the early 1950's, Turnbull ${ }^{[11]}$ found the solid/liquid interfacial energy $\sigma$ of pure $\mathrm{Sn}$ to be $0.0525 \mathrm{~J} / \mathrm{m}^{2}$ in a study of the nucleation rate of tin droplets. With the same method, the value was later corrected to $0.059 \mathrm{~J} / \mathrm{m}^{2}{ }^{[12]}$. An alternative way to derive solid/liquid interfacial energy is the depression of melting point method. With this method the interfacial energy of pure Sn was found to be $0.062 \pm 0.01 \mathrm{~J} / \mathrm{m}^{2}{ }^{[13]}$ or $0.069 \pm 0.006 \mathrm{~J} / \mathrm{m}^{2}{ }^{[14]}$. Since the nucleation rate method tends to underestimate $\sigma^{[15]}$, the latter two values are believed to be more reliable.

Not only are there large errors in experimental measurements of the solid/liquid interfacial energy, there is no way to determine its temperature dependence. Theoretical models ${ }^{[16-18]}$ can be utilized to overcome this problem. With Miedema's model ${ }^{[18]}$, the interfacial energy of pure $\mathrm{Sn}$ is presented as a linear function of temperature

$$
\sigma=0.027+7.723 \times 10^{-5} T
$$

This equation gives a value of $0.066 \mathrm{~J} / \mathrm{m}^{2}$ at the melting point $232^{\circ} \mathrm{C}$ and a value of $0.058 \mathrm{~J} / \mathrm{m}^{2}$ at $132^{\circ} \mathrm{C}$. Considering that the supercooling was about $100^{\circ} \mathrm{C}$ in nucleation frequency measurements ${ }^{[11]}$, equation (6) is consistent with most of the data reported in literature and provides, therefore, a good description of the interfacial energy $\sigma$ for pure tin.

The difference in composition at the interface between $\beta$-Sn and liquid solder introduces an extra contribution to the interfacial energy. Since the contents of Ag and $\mathrm{Cu}$ in $\mathrm{SnAgCu}$ solder are low, however, this contribution can be neglected and equation (6) is adopted in the kinetic simulation.

The free energy of nucleation $\Delta G$ and the critical nucleus size $r^{*}$ for $\beta$-Sn formation can now be calculated by combining Gibbs free energy difference $\Delta g$ in 
Fig. 5 and the interfacial energy $\sigma$ in equation (5). The results are plotted in Fig.6 and Fig.7.

\section{NUCLEATION RATE}

Two mechanisms of nucleation exist in supercooled liquid: homogeneous and heterogeneous nucleation. According to our calculation, however, the homogeneous nucleation rate is very low in solder interconnections, well below $10^{-70} \mathrm{~s}^{-1}$ at $170^{\circ} \mathrm{C}$, which is already $50^{\circ} \mathrm{C}$ lower than the equilibrium solidification temperature. Homogeneous nucleation of $\beta$-Sn can, therefore, hardly occur in solder interconnections during reflow soldering and heterogeneous nucleation at the $\mathrm{Liq} / \mathrm{Cu}_{6} \mathrm{Sn}_{5}$ interfaces is the only mechanism of initiating solidification of interconnections. Hence, we concentrate on heterogeneous nucleation rate in solder interconnections in this section.

The heterogeneous nucleation rate is expressed by the exponential kinetic expression

$$
I_{\text {heter }}=I_{\text {heter }}^{0} \exp \left(-\frac{\Delta G}{k_{B} T} f(\theta)\right)
$$

where $k_{B}$ is the Boltzmann's constant, $I_{\text {heter }}^{0}$ is a pre-exponential coefficient and $T$ is temperature. The activation energy is the free energy of nucleation $\Delta G$ discussed above.

In Equation (7), $f(\theta)$ is a function of the contact angle $\theta$ of the nucleus on a catalytic solid surface. When the catalytic surface is flat, $f(\theta)$ is written as

$$
f(\theta)=\frac{1}{4}(2+\cos \theta)(1-\cos \theta)^{2}
$$

If the interconnection does not contain any other impurities or foreign particles, the only site for heterogeneous nucleation is the $\mathrm{Liq} / \mathrm{Cu}_{6} \mathrm{Sn}_{5}$ interface.

Together with the free energy of nucleation presented in the previous section, the pre-coefficient $I_{\text {heter }}^{0}$ and the contact angle $\theta$ need to be known in the simulation of nucleation rate.

1) Pre-coefficient $I_{\text {heter }}^{0}$

The coefficient $I_{\text {heter }}^{0}$ can be calculated as ${ }^{[5]}$

$$
I_{\text {heter }}^{0}=\frac{n_{s} k_{B} T}{h} \exp \left(-\frac{\Delta G_{A}}{k_{B} T}\right)
$$

where $h$ is Plank's constant and $n_{s}$ is the number of atoms involved in nucleation. $\Delta G_{A}$ is the activation free energy for transporting an atom across the interface, which is approximately the same as the activation energy for viscous flow of liquid.

According to Seetharaman and Sichen ${ }^{[19]}$, the activation energy for viscous flow of liquid alloy can be computed by the equation

$$
\Delta G_{A}=\sum x_{i} \Delta G_{A, i}+\Delta^{m} G_{\text {mix }}+3 R T \cdot \sum \sum x_{i} x_{j}
$$

where $x$ is the mole fraction of each component, $\Delta G_{A, i}$ is the activation energy of liquid pure metal $i$ and $\Delta^{m} G_{\text {mix }}$ is the excess Gibbs energy of mixing. $\Delta G_{A}$ is therefore dependent on both temperature and liquid composition. Again with use of the thermodynamic databank system, $\Delta G_{A}$ for different silver contents of interconnections are plotted in Fig. 8. 
Assuming a simple cubic arrangement of interfacial atoms, $n_{s}$ can be calculated as

$$
n_{s}=A \cdot\left(\frac{V_{m}}{N}\right)^{-2 / 3}
$$

where $V_{m}$ is the molar volume of liquid and $A$ is the area of the $\mathrm{Liq} / \mathrm{Cu}_{6} \mathrm{Sn}_{5}$ interface. Because of the scallop-type growth of the $\mathrm{Cu}_{6} \mathrm{Sn}_{5}$ layer during soldering, $A$ is not equal to the projected interfacial area $A^{*}$ and a factor $\lambda$ should be added.

$$
A=\lambda A^{*}
$$

For $\mathrm{SnPb}$ solder, Zuruzi et al. ${ }^{[8]}$ have reported that $\lambda$ increases from 25 to 60 with increase in soldering time. Assuming that similar $\mathrm{Cu}_{6} \mathrm{Sn}_{5}$ morphology appears in SnAgCu interconnections, $\lambda$ is set to be 25 in the simulation.

For a solder droplet on a copper pan in DSC measurement ${ }^{[3]}$, the projected contact area between the solder droplet and the copper pan is approximately $5 \times 10^{-6} \mathrm{~m}^{2}$, while for typical solder interconnections the sum of the upper and lower solder/metallization interfacial areas is about $2 \times 10^{-7} \mathrm{~m}^{2}$. The kinetic simulation below is performed for these values of $A^{*}, 5 \times 10^{-6} \mathrm{~m}^{2}$ and $2 \times 10^{-7} \mathrm{~m}^{2}$.

\section{2) Contact Angle $\theta$}

No data is available for the contact angle $\theta$ of a $\beta$-Sn nucleus at the $\mathrm{Liq} / \mathrm{Cu}_{6} \mathrm{Sn}_{5}$ interface. Theoretically, the balance of three interfacial tensions, $\sigma_{S n / L}$, $\sigma_{L / C u_{6} S_{5}}$ and $\sigma_{S n / C u_{6} n_{5}}$, decides the value of the contact angle $\theta$ :

$$
\cos \theta=\frac{\sigma_{L / C u_{6} S n_{5}}-\sigma_{S n / C u_{6} S n_{5}}}{\sigma_{S n / L}}
$$

Unfortunately neither $\sigma_{L / C u_{6} S n_{5}}$ nor $\sigma_{S n / C u_{6} S n_{5}}$ is known exactly. Some theoretical models might be used to evaluate them, but the error goes completely out of control when the values are subtracted from each other, so that the contact angle cannot be estimated by this means. Instead, we simply apply different values of $\theta$ in the simulation and an estimate of $\theta$ will be obtained afterwards on the basis of a DSC measurement of the supercooling of solder droplets in a copper pan.

Fig.9 presents the simulated nucleation rates, with different contact angles, nominal contact areas, and silver contents.

\section{ACTUAL SOLIDIFICATION TEMPERATURE}

The simulated nucleation rates exhibit typical exponential-type variation over temperature. When the level of supercooling is low, the nucleation rate is so small that solidification is practically impossible. This situation prevails unless the temperature is below a critical range, where the nucleation rate ramps up by many orders of magnitude. In contrast to the equilibrium solidification temperature, the temperature at which solidification occurs is referred as the actual solidification temperature in this paper.

A critical value, $I^{*}$, can be assumed to exist as the lowest nucleation rate required for initiating solidification. The value of $I^{*}$ may be dependent on many factors and difficult to determine exactly. However, since even a small temperature fluctuation changes the rate of nucleation by several orders of magnitudes in the corresponding critical temperature range, only a rough estimate of $I^{*}$ is sufficient for determining the actual solidification temperature. 
Judging by the physical meaning of $I^{*}$, it should not depend on the size or composition of the liquid droplets nor on the mechanism of nucleation. Experimentally determined actual solidification temperatures of tin droplets in literature can be therefore utilised to evaluate the scale of $I^{*}$. Vonnegut ${ }^{[2]}$ observed that tin droplets ranging in diameters from $1 \mu \mathrm{m}$ to $10 \mu \mathrm{m}$ solidify at $125-132^{\circ} \mathrm{C}$. An additional simulation of the homogeneous nucleation rate in tin droplets, as shown in Fig.10, was therefore performed. As the figure shows, $125-132^{\circ} \mathrm{C}$ corresponds to the nucleation rates from $10^{-14}$ to $10^{-7} \mathrm{~s}^{-1}$. If we calculate the nucleation rate for $1 \mathrm{~mol}$ of liquid, the corresponding values will be $10^{-2}$ to $10^{5} \mathrm{~s}^{-1} \mathrm{~mol}^{-1}$, which is taken as the critical range of nucleation rate $I^{*}$.

The actual solidification of solder interconnections still cannot be estimated without knowing the exact value of the contact angle $\theta$, which strongly influences the simulated nucleation rate as shown in Fig. 9a. In a recent DSC measurement ${ }^{[3]}$, the solidification temperature of a $\mathrm{SnAgCu}$ solder droplet on a copper pan was found to lie between 204 and $208^{\circ} \mathrm{C}$. The composition of the solder was Sn0.61Ag0.4Cu $\left(x_{A g}=0.065\right)$ and the sample weights 6-12 mg, spreading over an area of approximately $5 \times 10^{-6} \mathrm{~m}^{2}$ on the copper pan. The simulated nucleation rate with $x_{A g}=0.065, A^{*}=5 \times 10^{-}$ ${ }^{6} \mathrm{~m}^{2}$ and $\theta=40^{\circ}$ (Fig. 9b) obtains a value between $10^{-2}$ to $10^{5} \mathrm{~s}^{-1} \mathrm{~mol}^{-1}$ at $205-207^{\circ} \mathrm{C}$, which is comparable to the measured solidification temperature. Hence, the contact angle $\theta$ of the $\beta$-Sn nucleus on $\mathrm{Cu}_{6} \mathrm{Sn}_{5}$ is assumed in the following to be $40^{\circ}$.

Finally, the estimated critical nucleation rate and contact angle for heterogeneous nucleation of $\beta$-Sn at $\mathrm{Liq} / \mathrm{Cu}_{6} \mathrm{Sn}_{5}$ interfaces allow us to predict the actual solidification temperatures of interconnections, as listed in Table.1. The solidification temperature decreases with the increase of Ag content. Since the liquid compositions of interconnections vary with temperature, and since the equilibrium solidification temperature depends on composition, the supercooling levels are calculated with use of the instantaneous equilibrium soldification temperature. As seen in Table 1, the supercooling level decreases slightly with the increase in the silver content, especially when the silver content is low.

Table 1. Predicted Solidification Temperature and Supercooling Level of Solder Interconnection.

\begin{tabular}{|c|c|c|c|c|}
\hline & \multicolumn{3}{|c|}{ Mole concentration of Ag in interconnection } \\
\cline { 2 - 5 } & 0.0065 & 0.01 & 0.02 & $0.035^{*}$ \\
\hline Actual solidification temperature $\left({ }^{\circ} \mathrm{C}\right)$ & $205-207$ & $204-206$ & $201-203$ & $198-201$ \\
\hline $\begin{array}{c}\text { Equilibrium temperature at the actual } \\
\text { solidification temperature }\left({ }^{\circ} \mathrm{C}\right)\end{array}$ & $226-230$ & $\sim 225$ & $\sim 222$ & $218-220$ \\
\hline $\begin{array}{c}\text { Supercooling level at the actual } \\
\text { solidification temperature }\left({ }^{\circ} \mathrm{C}\right)\end{array}$ & $21-23$ & $19-21$ & $19-21$ & $19-20$ \\
\hline $\begin{array}{c}\text { Temperature at which liquid } \\
\text { interconnection becomes supercooled } \\
\text { with respect to } \beta \text {-Sn }\left({ }^{\circ} \mathrm{C}\right)\end{array}$ & 225 & 224 & 221 & 217 \\
\hline $\begin{array}{c}\text { Extent of supercooling during reflow } \\
\text { soldering }\left({ }^{\circ} \mathrm{C}\right)\end{array}$ & $18-20$ & $18-20$ & $18-20$ & $17-20$ \\
\hline
\end{tabular}

The temperature range for this composition is the combination of the predicted temperature ranges under two different conditions: with and without $\mathrm{Ag}_{3} \mathrm{Sn}$ formation before the nucleation of $\beta$-Sn.

However, if the temperature at which the liquid interconnection becomes supercooled with respect to $\beta$-Sn is considered, approximately the same temperature range at which interconnections are supercooled during reflow soldering, $18-20^{\circ} \mathrm{C}$, is obtained. The equilibrium temperatures at which supercooling commences is determined by calculating thermodynamically the $\beta-\mathrm{Sn}+\mathrm{Cu}_{6} \mathrm{Sn}_{5}$ binary eutectic monovariant line in the SnAgCu phase diagram and has been presented in Fig.3. 
Thus, the actual solidification temperatures of solder interconnections can be directly estimated from the phase equilibria information as shown in Fig.11.

\section{DISCUSSION}

The influences of cooling rate, interconnection size, morphology of the intermetallic layer, and component metallizations or boards/metal finishes on the actual solidification temperature are discussed below.

\section{1) Cooling rate}

The nucleation rate in Equation (7) is a function of temperature and not related to cooling rate. Since a certain period of time is always required to initiate solidification and since faster cooling rate causes a greater temperature drop, the observed starting point of solidification during continuous cooling is dependent on the cooling rate. This is probably the main reason why the critical nucleation rate cannot be exactly known and a range of $I^{*}$ value has to be applied.

For normal cooling rate, however, the range of critical nucleation rates $10^{-2}$ to $10^{5} \mathrm{~s}^{-1} \mathrm{~mol}^{-1}$ is believed to be wide enough to accommodate such variation in cooling rate. It means that the change of cooling rate can only cause a variation of $1-2^{\circ} \mathrm{C}$ in the predicted solidification temperature. This has also been confirmed in DSC measurements, which showed little difference in solidification temperatures when the cooling rate was $1^{\circ} \mathrm{C} / \mathrm{s}$ and $5^{\circ} \mathrm{C} / \mathrm{s}{ }^{[3]}$. The cooling rate during reflow soldering varies within just $1-3^{\circ} \mathrm{C} / \mathrm{s}$, which further limits the influence of cooling rate.

\section{2) Interconnection Size}

As discussed above, the heterogeneous nucleation rate of a solder droplet is proportional to the nominal area of the $\mathrm{Liq} / \mathrm{Cu}_{6} \mathrm{Sn}_{5}$ interface. The nominal area $A^{*}$ for typical solder interconnections is one order smaller than that of the DSC samples, being only about $2 \times 10^{-7} \mathrm{~m}^{2}$. The difference between the nucleation rates is insignificant, however, compared with the wide range of the critical nucleation rate $10^{-2}$ to $10^{5} \mathrm{~s}^{-1} \mathrm{~mol}^{-1}$. It may be concluded that the actual solidification temperature drops only $0.5-1^{\circ} \mathrm{C}$ when the nominal interfacial area $A^{*}$ becomes 10 times smaller.

3) Morphology of the Intermetallic Layer

The simulation of nucleation rates above assumes that the $\mathrm{Liq} / \mathrm{Cu}_{6} \mathrm{Sn}_{5}$ interfaces are flat. This is supported by the fact that the critical size of $\beta$-Sn nucleus is in the order of $10^{-8} \mathrm{~m}$ except at very low supercooling level as shown in Fig.7, which is by far smaller than the radius of $\mathrm{Cu}_{6} \mathrm{Sn}_{5}$ grains formed during reflow soldering. It means that Equation (8) is always applicable during the nucleation on interconnections, no matter what kind of morphology of the interfaces has been developed. Hence, the only influence of scallop-type $\mathrm{Cu}_{6} \mathrm{Sn}_{5}$ growth on the actual solidification temperature may come from the increase of the actual to projected $\mathrm{Liq} / \mathrm{Cu}_{6} \mathrm{Sn}_{5}$ areas ratio $\lambda$. For an $\mathrm{SnPb}$ interconnection, it is reported that $\lambda$ increases from 25 at the beginning to 60 after 25 hours above liquidu temperature ${ }^{[9]}$. Such a small increase in the actual $\mathrm{Liq} / \mathrm{Cu}_{6} \mathrm{Sn}_{5}$ area can only cause negligible variation in the predicted solidification temperature. The morphology of the intermetallic layer has little effect, therefore, on the solidification temperature of the interconnection.

4) Component metallizations and boards/metal finishes

In some cases, the intermetallic compound to be formed at the interfaces is altered for different component metallizations or boards/metal finishes. As an 
example, when $\mathrm{Ni}(\mathrm{P}) / \mathrm{Au}$ metallization is used, a large amount of $\mathrm{Ni}$ is dissolved in the intermetallic layer and the compound formed is $(\mathrm{Cu}, \mathrm{Ni})_{6} \mathrm{Sn}_{5}$ instead of $\mathrm{Cu}_{6} \mathrm{Sn}_{5}{ }^{[20]}$. The composition of the liquid that is in equilibrium with the intermetallic layer differs accordingly. Furthermore, the contact angle $\theta$ may also be changed on different nucleating surface of intermetallic compound. As shown in Fig. 9a, the nucleation rate is highly sensitive to the contact angle. In the range $30-50^{\circ}, 1^{\circ}$ difference in the contact angle correlates with $1^{\circ} \mathrm{C}$ difference in the actual solidification temperature. Nevertheless, the actual solidification temperature of interconnections for different intermetallic layer can be analyzed similarly in the same way presented in this paper, which is an interesting point for further investigations.

The actual solidification temperature of interconnections, therefore, should not be significantly changed with the variation of cooling rate, interconnection size and morphology of $\mathrm{Cu}_{6} \mathrm{Sn}_{5}$ layer. The prediction in Fig. 11 applies as long as the same type of intermetallic compound, $\mathrm{Cu}_{6} \mathrm{Sn}_{5}$, is formed at the interfaces between bulk solder and component metallizations or boards/metal finishes.

\section{SUMMARY}

The nucleation energy for $\beta$-Sn formation was evaluated by referring to the thermodynamics of near-eutectic SnAgCu solder droplets on copper surface. Since the homogeneous nucleation rate was found to be extremely low, it follows that the solidification temperatures are controlled by the kinetics of heterogeneous nucleation at $\mathrm{Liq} / \mathrm{Cu}_{6} \mathrm{Sn}_{5}$ interfaces. With the free energy of nucleation available, the nucleation rates could be simulated on the basis of classical nucleation theory. They are presented with as exponential functions of temperature, which increases over many orders of magnitude within a narrow temperature range.

By combining the results of an additional simulation of the homogeneous nucleation rates in tin droplets with measured values of the supercooling of the droplets reported in literature, we estimated a range from $10^{-2}$ to $10^{5} \mathrm{~s}^{-1} \mathrm{~mol}^{-11}$ as the critical nucleation rates for solidification.

At the same time, using the results of DSC measurements we obtained about $40^{\circ}$ for the value of the contact angle for heterogeneous $\beta$-Sn nucleation at the $\mathrm{Liq} / \mathrm{Cu}_{6} \mathrm{Sn}_{5}$ interface. From these results the temperature of solidification of liquid solder on copper can be predicted. The extent of the supercooling was found to be more or less constant about $18-20^{\circ} \mathrm{C}$. Since the supercooling range was only weakly dependent on cooling rate, interconnection size, and the morphology of intermetallic phases at $\mathrm{Liq} / \mathrm{Cu}_{6} \mathrm{Sn}_{5}$ interfaces, the solidification temperatures of interconnections can be finally predicted on the basis of phase equilibria in the SnAgCu solder system.

\section{Reference}

1. J.K.Kivilahti, "The Chemical Modelling of Electronic Materials and Interconnections”, Journal of Metals, vol. 54, 2002, No.12, pp. 52-57, 2002.

2. B. Vonnegut, "Variation with Temperature of the Nucleation Rate of Supercooled Liquid Tin and Water Drops”, J. Colloid Sci., 3, pp.563-569, 1948.

3. Koivisto, J., M.S. Thesis., Helsinki University of Technology (2004).

4. D.Turnbull, "Formation of Crystal Nuclei in Liquid Metals", Journal of Applied Physics, 21, pp.1022-1028, 1950.

5. B.Cantor and R.D.Doherty, "Heterogeneous Nucleation in Solidifying Alloys", Acta Metallurgica., Vol. 27, pp. 33-46,1979. 
6. H.Yu and J.Kivilahti, "CFD Modelling of the Flow Field inside Reflow Oven", Journal of Soldering \& Surface Mount Technology, Vol. 14, No. 1, pp. 38-44, 2002.

7. H.Yu, T.T.Mattila and J.K.Kivilahti, "Thermal Simulation of the Solidification of Lead-free Solder Interconnections”, to be published in IEEE Transactions on Components and Packaging Technologies.

8. W.Kurz and D.J.Fisher, "Fundamentals of Solidification", Fourth revised edition, Appendix 2, ISBN 0-87849-804-4, Trans Tech Publications Ltd, Switzerland, 1998.

9. A.S.Zuruzi, C.-h.Chiu, S.K.Lahiri and K.N.Tu, "Roughness Evolution of $\mathrm{Cu}_{6} \mathrm{Sn}_{5}$ Intermetallic during Soldering”, Journal of Applied Physics, 86, No.9, 4916-4921, 1999.

10. J.-O.Andersson, T.Helander, L.Höglund, P.F.Shi, and B.Sundman, “Thermo-Calc \& DICTRA, Computational Tools for Materials Science”, Calphad, Vol.26, No.2, pp. 273-312, 2002.

11. Turbull, B., "Isothermal Rate of Solidification of Small Droplets of Mercury and Tin”, J. Chem. Phys., 18, 768 (1950).

12. V.Scripov, "Crystal Growth and Materials", edited by E.Kaldis and H.Scheel, Amsterdam, North-Holland, pp.327, 1977.

13. C.R.M.Wronski, "The Size Dependence of the Melting Point of Small Particles of Tin”, Brit. J. Appl. Phys., Vol.18, pp.1731-1737, 1967.

14. R.P.Berman and A.E.Curzon, "The Size Dependence of the Melting Point of Small Particles of Indium”, Can. J. Phys., Vol.52, No.11, pp.923-929, 1974.

15. N.Eustathopoulos, "Energetics of Solid/Liquid Interfaces of Metals and Alloys", International Metals Reviews, Vol.28, No.4, pp.189-210, 1983.

16. R.H.Ewing, "The Free Energy of the Crystal-Melt Interface from the Radial Distribution Function”, J. Crystal Growth, Vol.11, pp.221-224, 1971.

17. Y.Waseda and W.A.Miller, "Calculation of the Crystal-Melt Interfacial Free Energy from Experimental Radial Distribution Function Data”, Trans. Jpn. Inst. Met., 19, 546, 1978.

18. A.R.Miedema and F.J.A.den Broeder, "On the Interfacial Energy in Solid-Liquid and Solid-Solid Metal Combinations”, Z.Metallkde., Vol.70, No.1, pp.14-20, 1979.

19. S.Seetharaman and DU Sichen, "Estimation of the Viscosities of Binary Metallic Melts Using Gibbs Energies of Mixing”, Metallurgical and Materials Transaction, Vol.25B, pp.589-595, 1979.

20. K. Zeng, V. Vuorinen, and J. K. Kivilahti, “ Interfacial Reactions Between LeadFree SnAgCu Solder and Ni(P) Surface Finish on Printed Circuit Boards”, IEEE Transactions on Component, Packaging and Manufacturing Technology, 25, 162, 2002. 
Manuscript to be published in IEEE Transaction on Component and Packaging Technologies, with permission from IEEE.

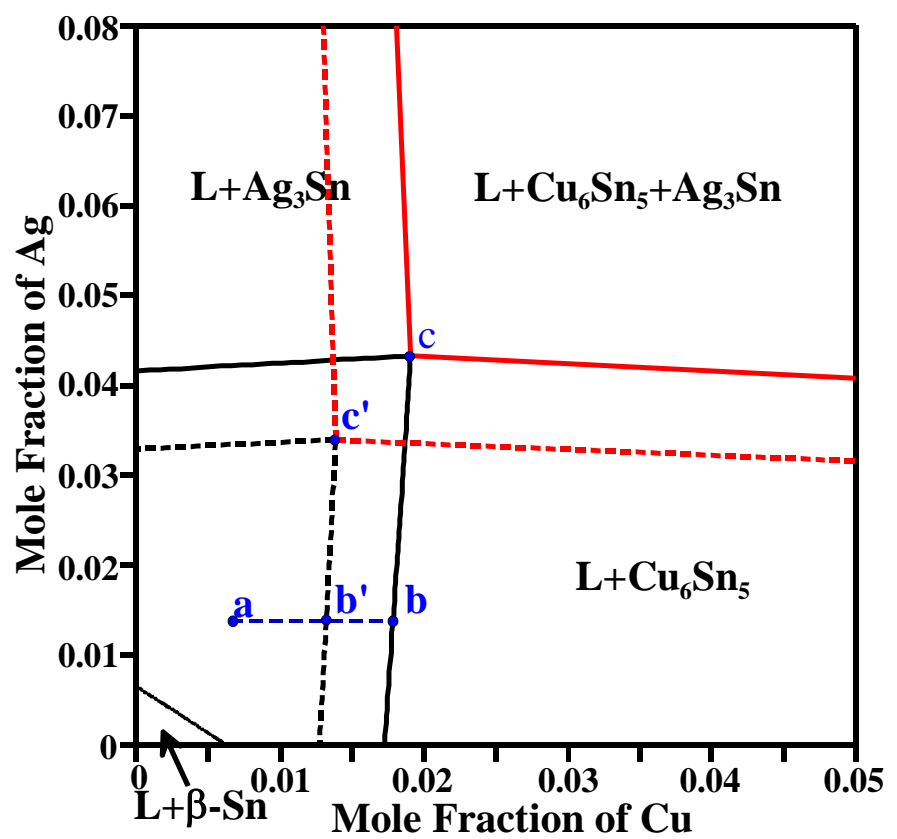

Fig.1 Sn corner of calculated isothermal sections of $\mathrm{SnAgCu}$ phase diagram at $230^{\circ} \mathrm{C}$ (solid line) and $210^{\circ} \mathrm{C}$ (dotted line, $\beta$-Sn phase is suspended).

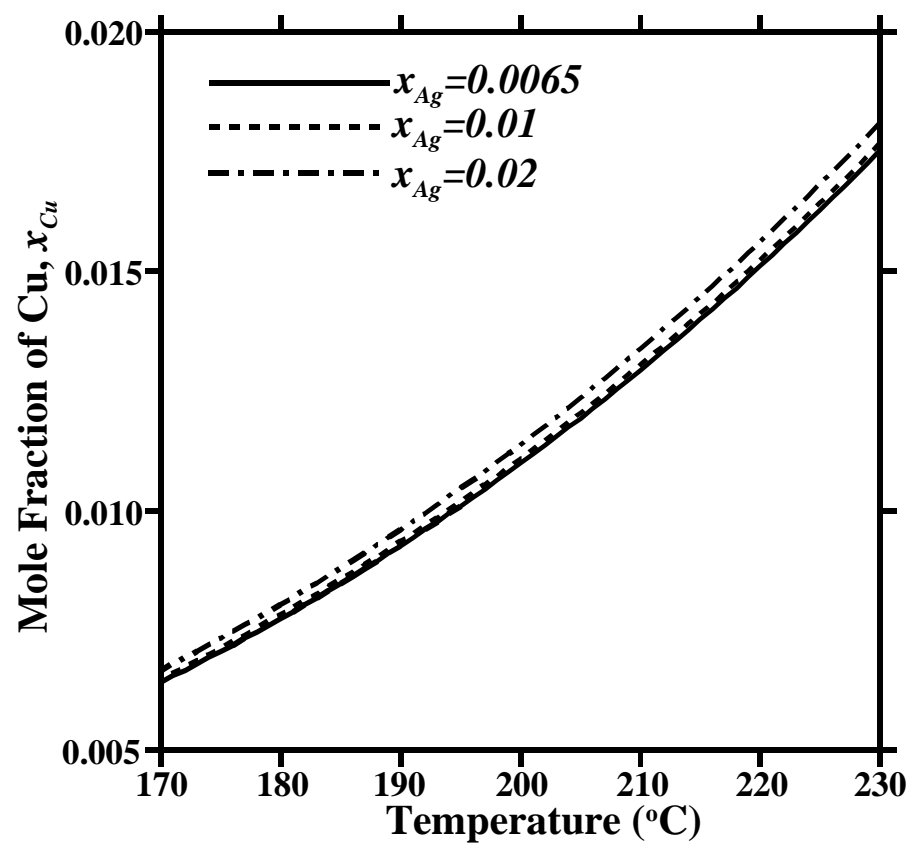

Fig.2 Calculated liquid copper content $x_{C u}$ of interconnection. 
Manuscript to be published in IEEE Transaction on Component and Packaging Technologies, with permission from IEEE.

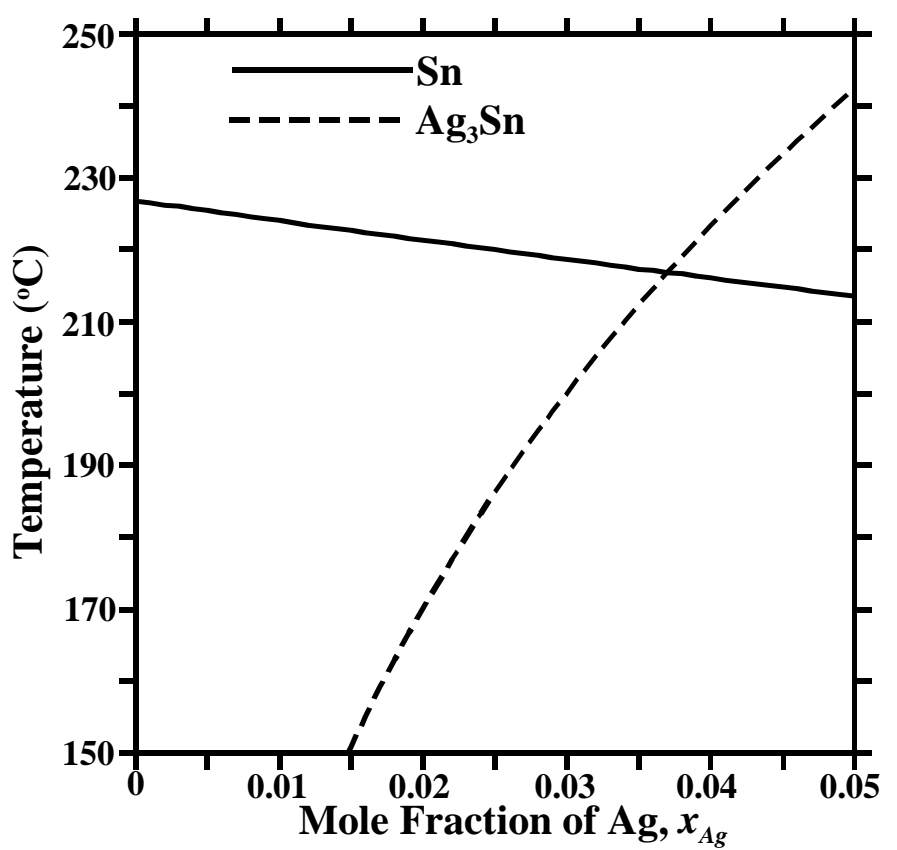

Fig.3 Temperature at which the driving force for independent $\beta$-Sn or $\mathrm{Ag}_{3} \mathrm{Sn}$ nucleation appears, determined by the calculated temperature of binary eutectic reaction $\mathrm{L} \Rightarrow \mathrm{Cu}_{6} \mathrm{Sn}_{5}+\mathrm{Ag}_{3} \mathrm{Sn}$ (suspending $\beta$-Sn) or $\mathrm{L} \Rightarrow \mathrm{Cu}_{6} \mathrm{Sn}_{5}+\beta$-Sn (suspending $\left.\mathrm{Ag}_{3} \mathrm{Sn}\right)$. 
Manuscript to be published in IEEE Transaction on Component and Packaging Technologies, with permission from IEEE.

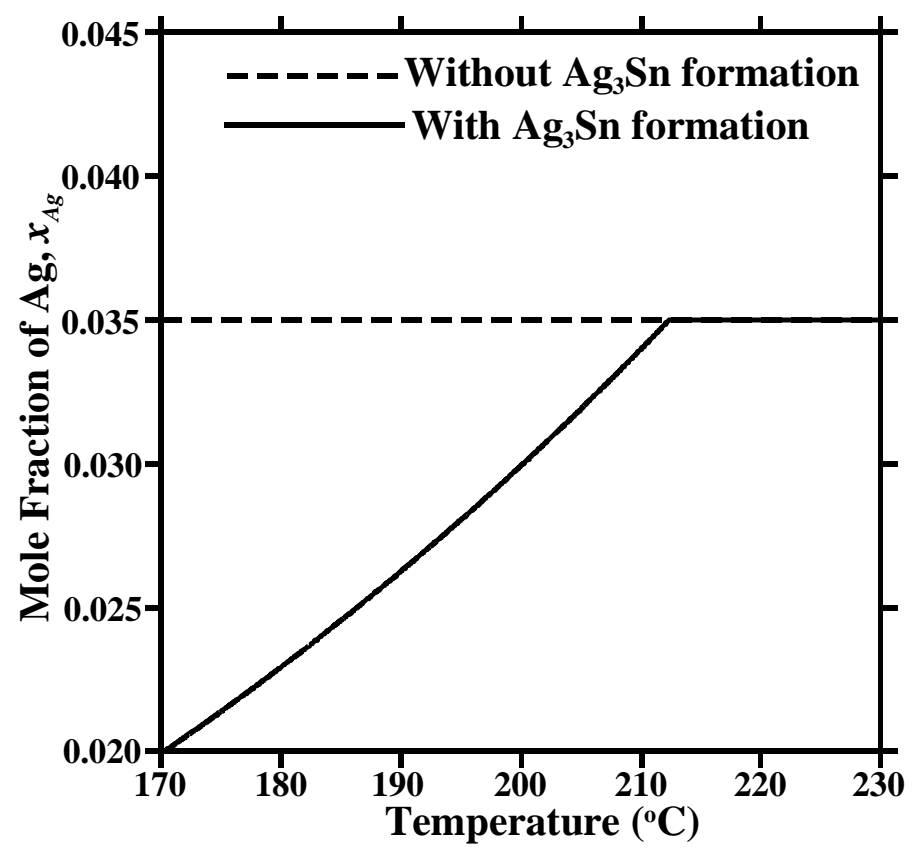

(a)

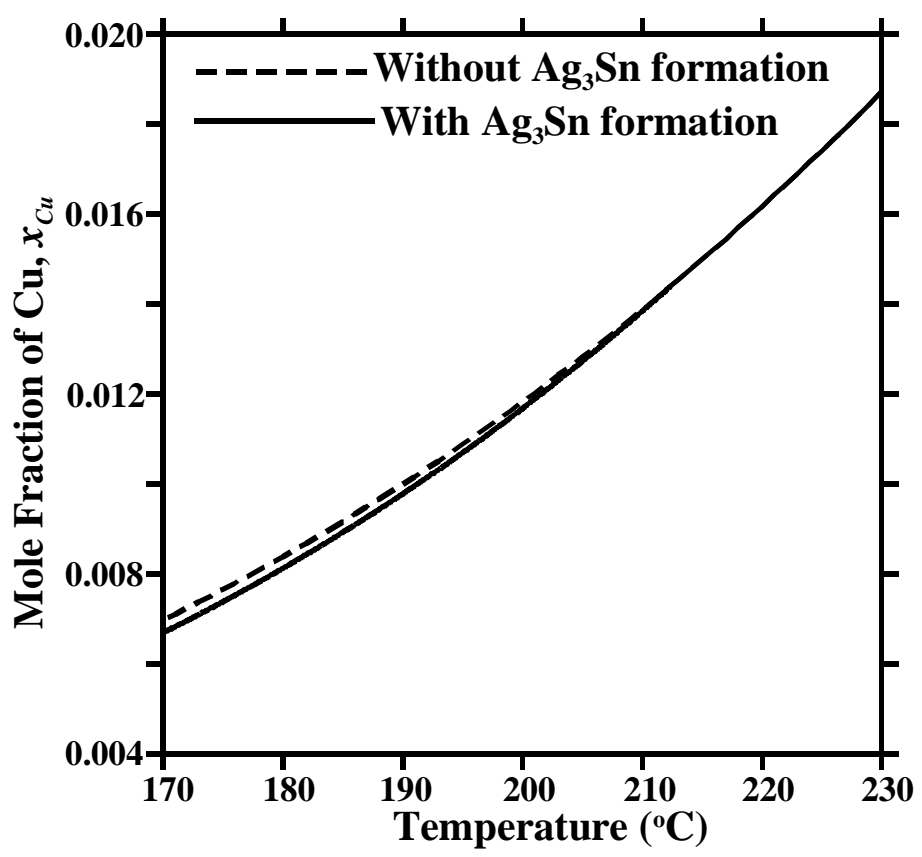

(b)

Fig.4 Calculated liquid composition of interconnection with different assumptions about $\mathrm{Ag}_{3} \mathrm{Sn}$ formation. The original Ag content of solder alloy is 0.035.
(a) Silver Content;
(b) Copper Content. 


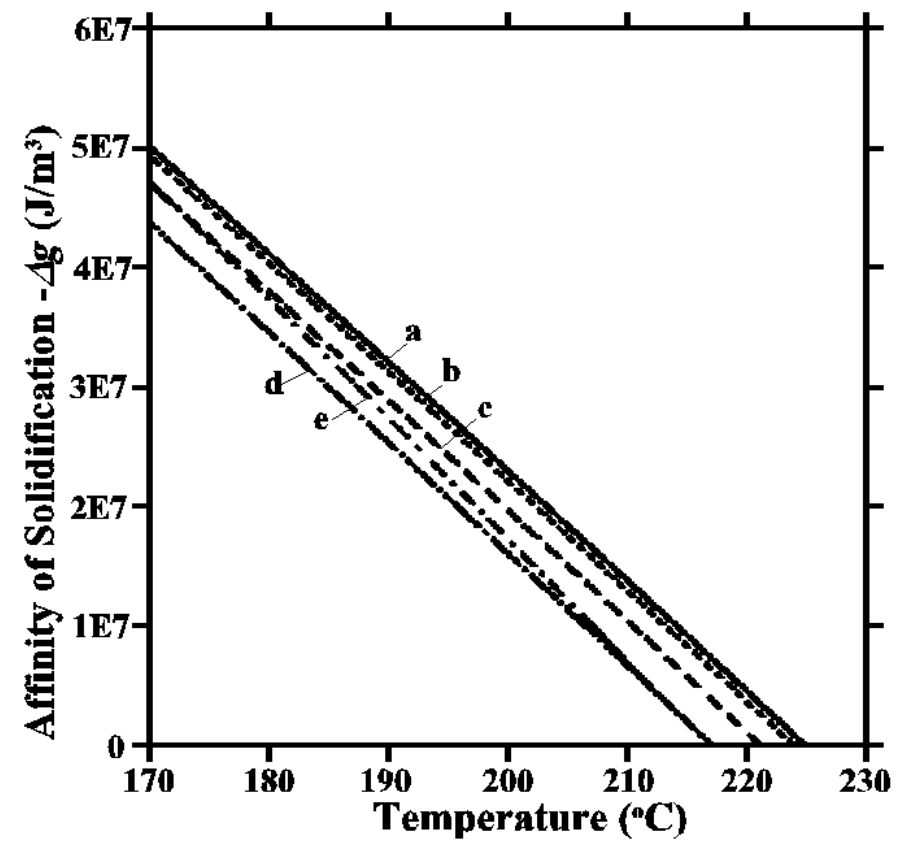

Fig.5 Affinity of solidification (the opposite value of driving force $\Delta g$ ) per unit volume of $\beta$-Sn nucleation.
a: $x_{A g}=0.0065$;
b: $x_{A g}=0.01$;
c: $x_{A g}=0.02$;
$\mathrm{d}: x_{A g}=0.035$, without $\mathrm{Ag}_{3} \mathrm{Sn}$ formation;
e: $x_{A g}=0.035$, with $\mathrm{Ag}_{3} \mathrm{Sn}$ formation.

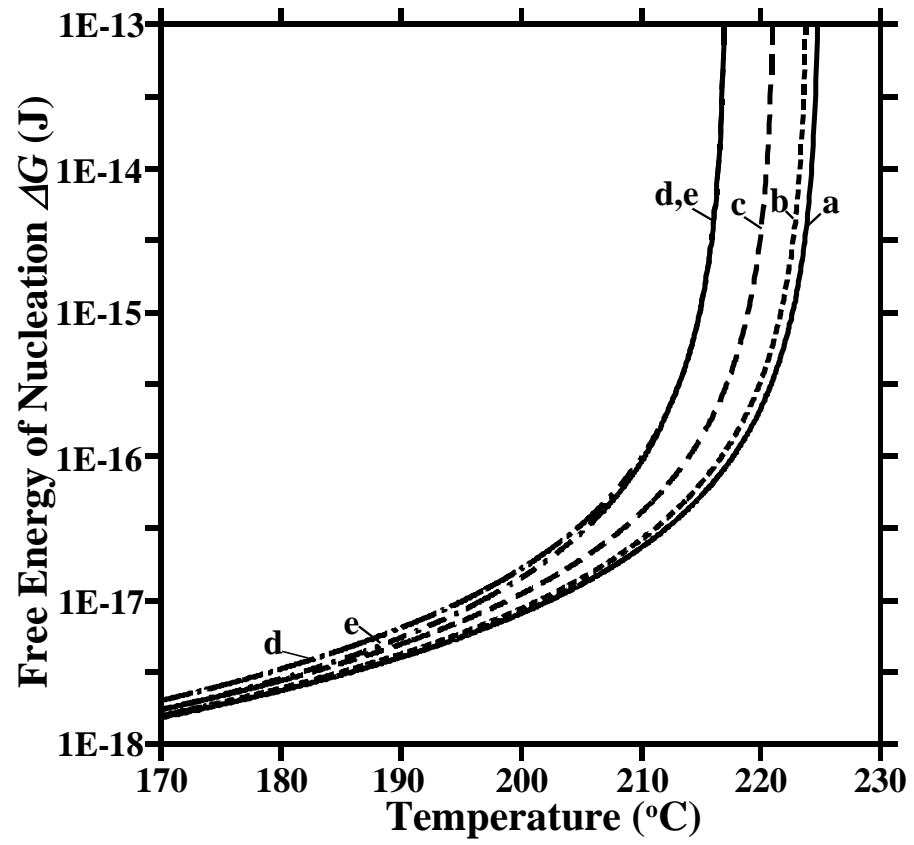

Fig.6 Free energy of nucleation $\Delta G$ of $\beta$-Sn.
a: $x_{A g}=0.0065$;
b: $x_{A g}=0.01$;
c: $x_{A g}=0.02$;
d: $x_{A g}=0.035$, without $\mathrm{Ag}_{3} \mathrm{Sn}$ formation;
e: $x_{A g}=0.035$, with $\mathrm{Ag}_{3} \mathrm{Sn}$ formation. 


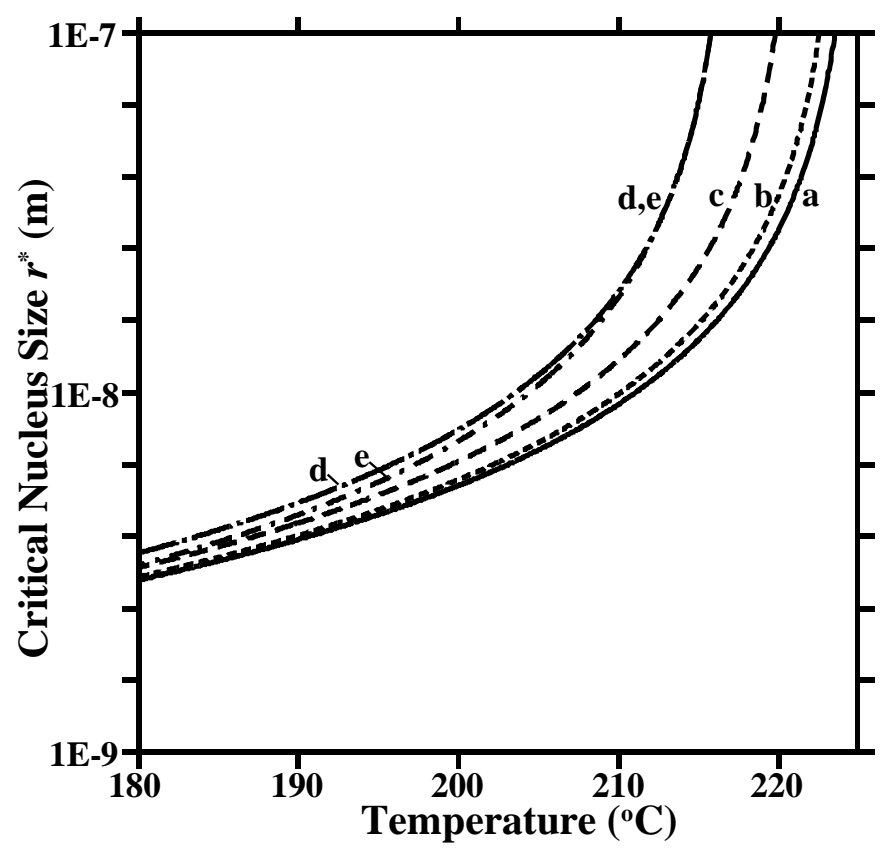

Fig.7 Critical nucleus size $r^{*}$ of $\beta$-Sn nucleation.
a: $x_{A g}=0.0065$;
b: $x_{A g}=0.01$;
c: $x_{A g}=0.02$;
d: $x_{A q}=0.035$, without $\mathrm{Ag}_{3} \mathrm{Sn}$ formation;
e: $x_{A g}=0.035$, with $\mathrm{Ag}_{3} \mathrm{Sn}$ formation.

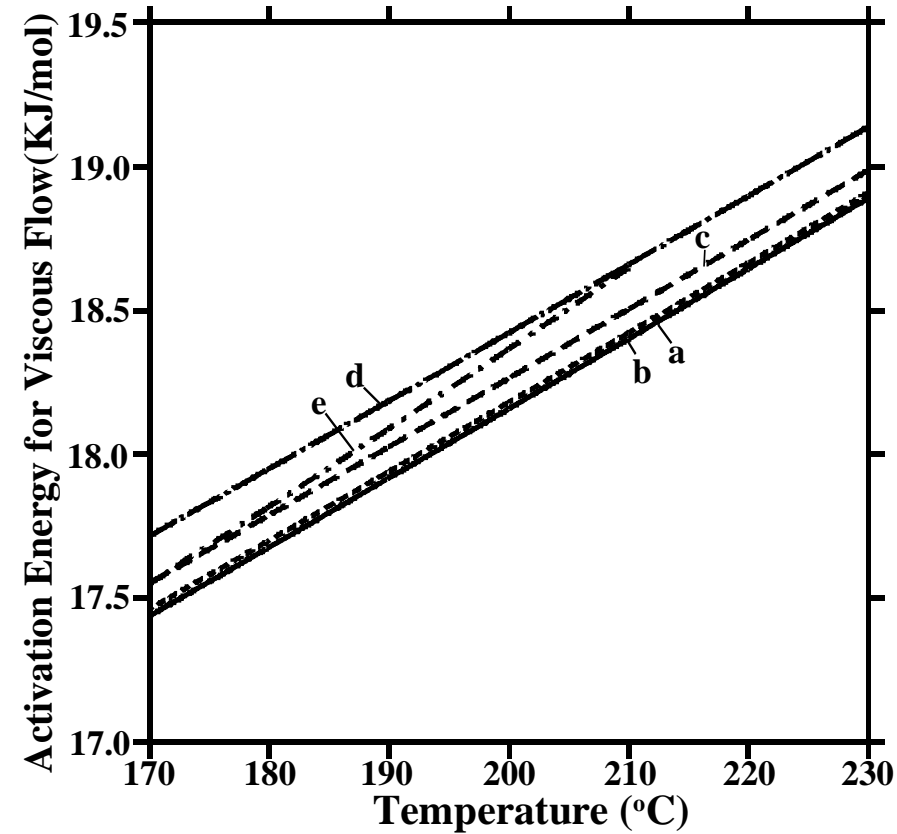

Fig.8 Activation energy for viscous flow of liquid interconnection.
a: $x_{A q}=0.0065$
b: $x_{A g}=0.01$
c: $x_{A g}=0.02$
d: $x_{A g}=0.035$, without $\mathrm{Ag}_{3} \mathrm{Sn}$ formation;
e: $x_{A g}=0.035$, with $\mathrm{Ag}_{3} \mathrm{Sn}$ formation. 
Manuscript to be published in IEEE Transaction on Component and Packaging Technologies, with permission from IEEE.

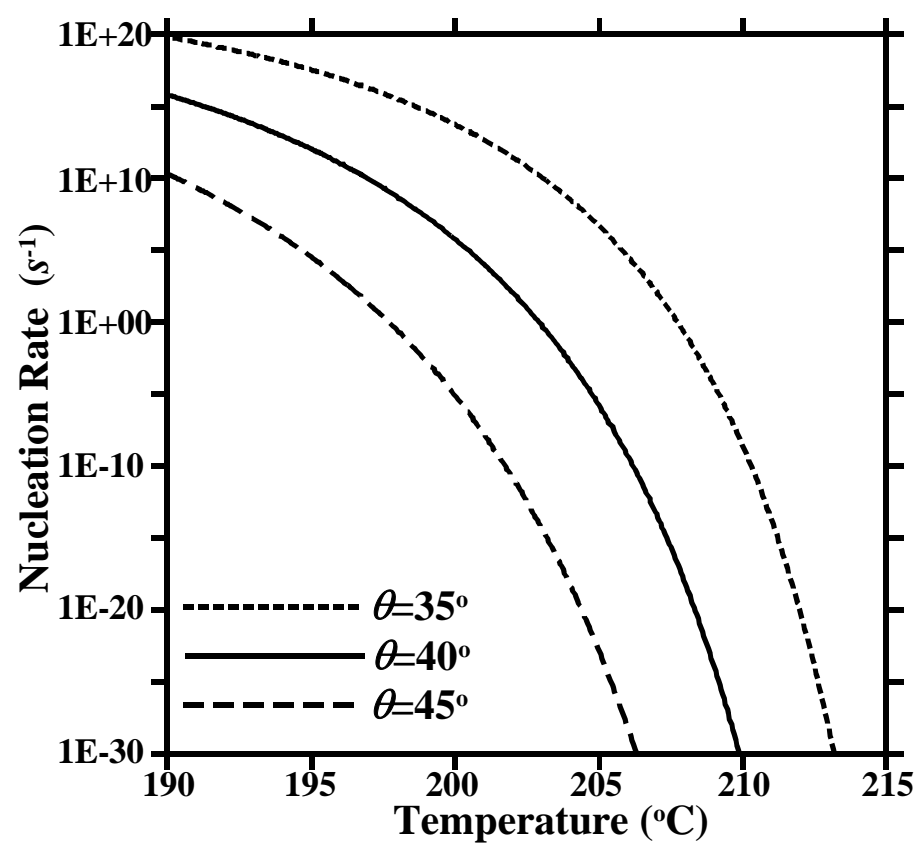

(a)

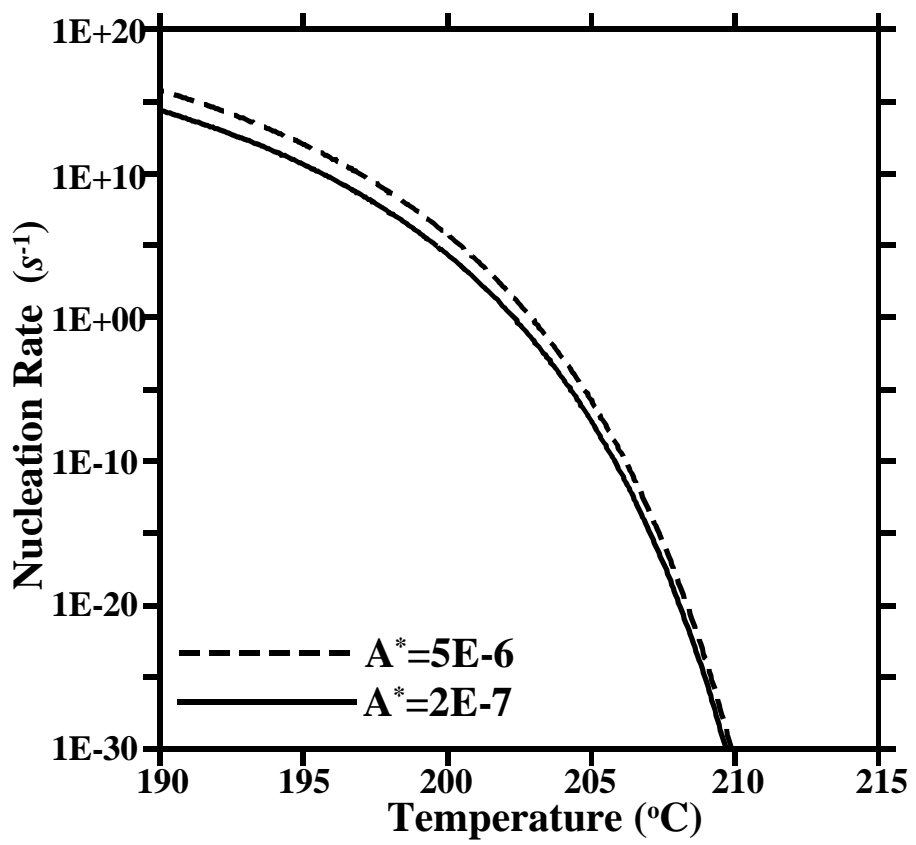

(b) 


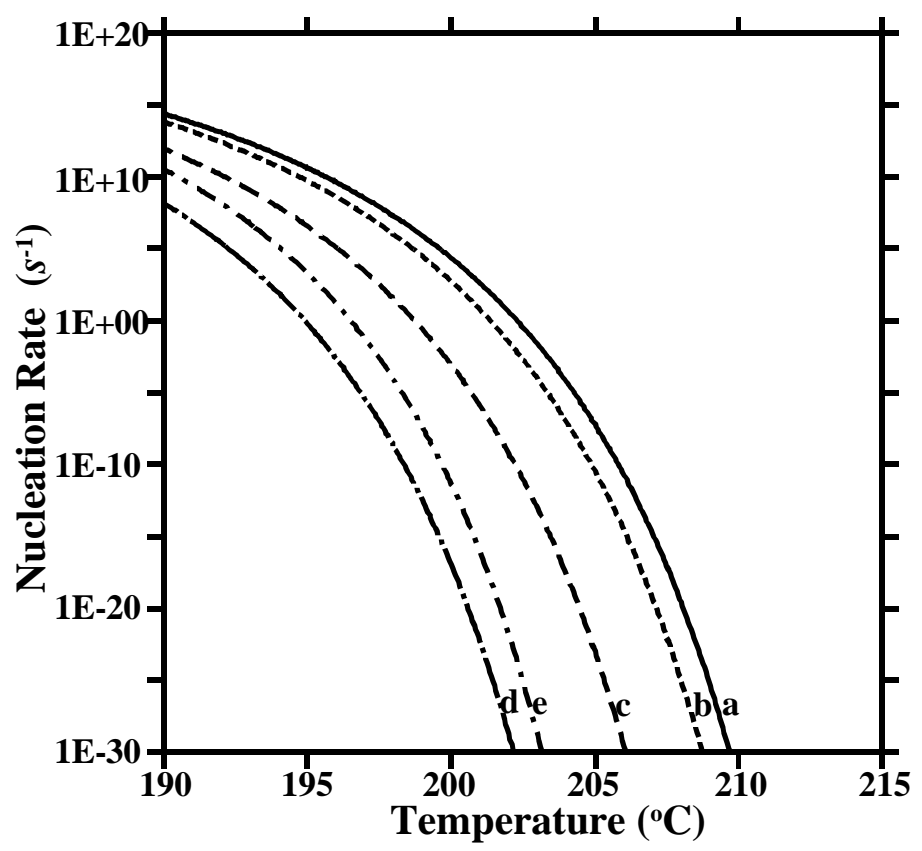

(c)

Fig.9 Some results of calculated nucleation rate, with different assumed contact angle, nominal contact area, and silver content.

(a) Different contact angle, $A^{*}=5 \times 10^{-6} \mathrm{~m}^{2}$ and $x_{A g}=0.0065$;

(b) Different nominal contact area, $\theta=40^{\circ}$ and $x A g=0.0065$;

(c) Different silver content (a-e marked in the same way as Fig.7), $\theta=40^{\circ}$ and $A^{*}=2 \times 10^{-7} \mathrm{~m}^{2}$. 


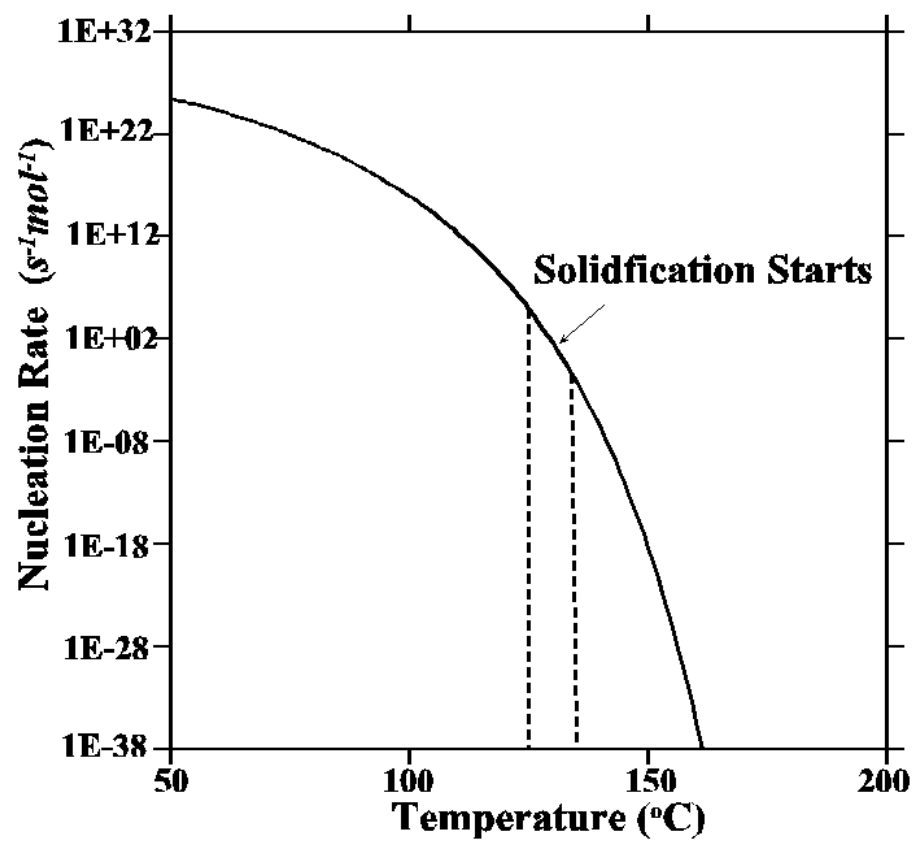

Fig.10 Calculated nucleation rate of pure tin droplet with diameter $5 \mu \mathrm{m}$.

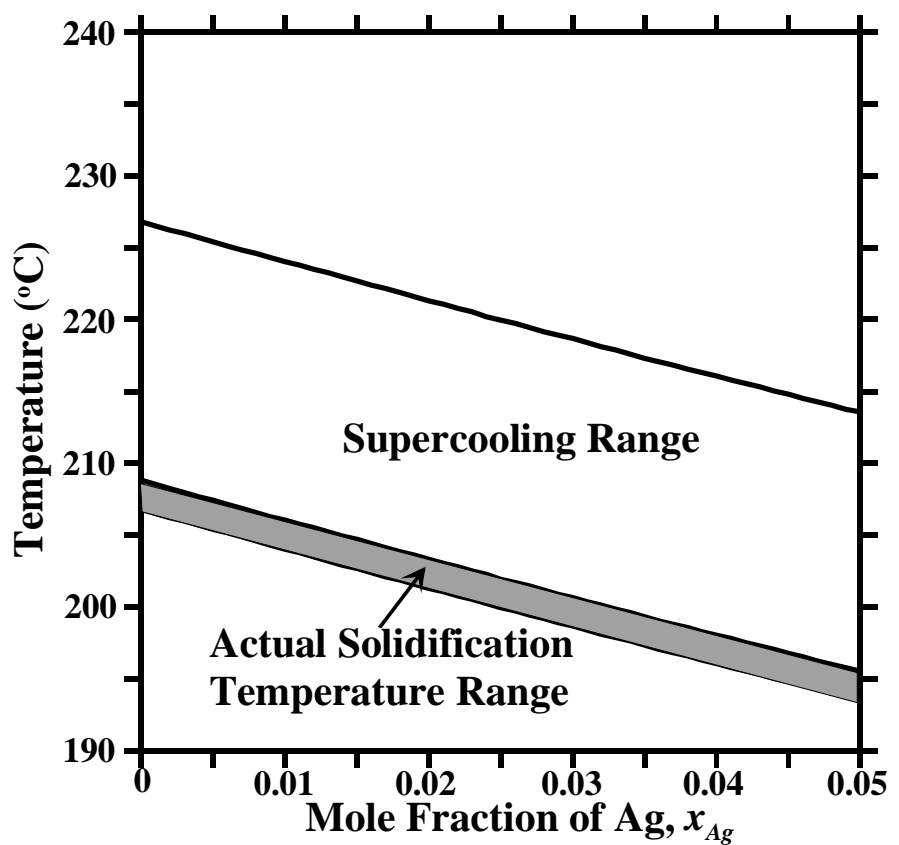

Fig.11 Predicted actual solidification temperature of $\mathrm{SnAgCu}$ solder interconnections during reflow soldering. 